\title{
The relationship between recurrent implantation failure and sexual function in infertile Iranian women: A case-control study
}

\section{Samira Ghorbani}

Ahvaz Jundishapur University of Medical Sciences: Ahvaz Jondishapour University of Medical Sciences Khadijeh Hekmat

Ahvaz Jundishapur University of Medical Sciences: Ahvaz Jondishapour University of Medical Sciences

Parvin Abedi ( $\sim$ parvinabedi@ymail.com )

Ahvaz Jondishapour University of Medical Sciences https://orcid.org/0000-0002-6980-0693

\section{Saeed Ghanbari}

Ahvaz Jundishapur University of Medical Sciences: Ahvaz Jondishapour University of Medical Sciences

Narjes Dibavand

Ahvaz Jundishapur University of Medical Sciences: Ahvaz Jondishapour University of Medical Sciences

\section{Research}

Keywords: Recurrent implantation failure, Sexual function, Infertility

Posted Date: September 29th, 2021

DOI: https://doi.org/10.21203/rs.3.rs-936595/v1

License: (c) (1) This work is licensed under a Creative Commons Attribution 4.0 International License. Read Full License 


\section{Abstract \\ Background}

Recurrent implantation failure affects $3-5 \%$ of women, which means failing to implant after two or more high-quality embryo transfer cycles. The aim of this study was to assess the relationship between recurrent implantation failure and sexual function in infertile Iranian women.

\section{Methods}

This was a case-control study of 180 infertile Iranian women (90 infertile women with recurrent implantation failure and 90 infertile women with no implantation failure). A demographic questionnaire and the Female Sexual Function Index were used for data collection. Data analyzed by means of chisquare, independent t-test and linear regression.

\section{Results}

The mean scores of different domains of sexual function including (desire, lubrication, arousal, orgasm, pain, satisfaction) were significantly lower in the group with RIF compared to the group without RIF. The total score of sexual function was significantly lower in the RIF group than in the RIF-free group (23.11 \pm 2.24 , vs. $25.99 \pm 2.35, p<0.001)$. Women in the RIF group were 2.65 times more likely to have a low score of sexual function compared to the women with no RIF $(p<0.001)$.

\section{Conclusion}

Women experiencing recurrent implantation failure may be at particular risk for reduced sexual function. Sexual function issues should be treated as an important component of comprehensive care.

\section{Plain Language Summary}

Recurrent implantation failure means failing to implant after two or more high-quality embryo transfer cycles. The aim of this study was to assess the relationship between recurrent implantation failure and sexual function in infertile Iranian women. In this study 180 infertile Iranian women (90 infertile women with recurrent implantation failure and 90 infertile women with no implantation failure) were recruited. A demographic questionnaire and the Female Sexual Function Index were used for data collection. The mean scores of different domains of sexual function including (desire, lubrication, arousal, orgasm, pain, satisfaction) were significantly lower in the group with recurrent implantation failure compared to the group without. The total score of sexual function was significantly lower in the recurrent implantation failure group than in the group without. Women in the recurrent implantation failure group were 2.65 times more likely to have a low score of sexual function compared to the women with no recurrent 
implantation failure. Women experiencing recurrent implantation failure may be at particular risk for reduced sexual function. Sexual function issues should be treated as an important component of comprehensive care.

\section{Background}

Infertility is one of the crises of married life that the World Health Organization defined as a disease of the reproductive system, failure to achieve pregnancy after 12 months or more of unprotected regular sexual intercourse (1). In vitro fertilization (IVF) is often the best solution for many couples with different types of infertility (2). Only one-third of women receiving IVF treatment will develop an intra-uterine pregnancy (3). However, a significant number of patients remain subject to recurrent implantation failure (RIF) (4). RIF affects $3-5 \%$ of women, which in several studies defined in the absence of implantation following two or more high-quality embryo transfer cycles, intracytoplasmic injection of sperm, or frozen embryos (5-6). The prevalence of RIF in developed countries is 3-4\%, in developing countries $6-7 \%$ and in Iran is about $5-8 \%(7)$. Women with RIF are more likely to experience anxiety $(86 \%)$, depression $(40.8 \%)$, stress $(24 \%)$, and decreased quality of life (70\%), which can lead to sexual dysfunction in women (8-9).

The human sexual response cycle is a physiological process that includes the stages of desire, arousal, orgasm, and suppression. Sexual dysfunction is defined as any problem that occurs in this cycle or fails to reach orgasm (10). The prevalence of sexual dysfunction in a domestic study in Iran was reported at $31.5 \%$ (11). Women with sexual dysfunction experience mood instability, anxiety, stress, and reduction in life satisfaction (12). According to previous studies, the rate of anxiety and depression in women with implant failure due to uncertainty about the cause of failure, financial problems and the duration of retreatment, is maximized (13). There is a significant relationship between the seriousness of depression and anxiety with female sexual satisfaction and performance. This means that with the increase of depression and anxiety, the rate of sexual dysfunction increases and the marital relationship in women is done solely for the purpose of having children without any satisfaction in the relationship (14). On the other hand, following implantation failure, higher stress levels and lower quality of life have been reported, and increased stress and reduced quality of life lead to sexual dysfunction and decreased sexual satisfaction (15-16). Furthermore, ovarian stimulant drugs that used in the infertility treatment process, followed by implantation failure, will cause hormonal changes and a decrease in hormones that affect sexual function, which may lead to sexual dysfunction in women (17). Numerous studies show that long-term treatments for infertility lead women to have negative self-beliefs, concerns about sexual appeal, feelings of rejection, sexual dysfunction, and marital problems (18). Most studies have focused on the effect of one-time IVF failure on quality of life, stress, anxiety and depression and sexual function (19), and there is little data on the relationship between recurrent infertility treatment failure and sexual function. As a result, this study was designed to assess the relationship between recurrent implantation failure and sexual function among infertile Iranian women.

\section{Materials And Methods}




\section{Study design}

This study was a case-control study involving 180 infertile women who referred to infertility clinics in Ahvaz, Iran. The study commenced in October and concluded in November 2020. The design of the study was approved by the Ethics Board of the Ahvaz Jundishapur University of Medical Sciences (Ref: IR.AJUMS.REC.1399.073). This study was conducted in two infertility clinics in Ahvaz.

\section{Participant}

In this study, we recruited infertile women with a history of recurrent implantation failure (90) and infertile women with no recurrent implantation failure $(n=90)$. Inclusion criteria were as follows: age between 18 and 45 years, basic literacy, at least one year has passed from the infertility, without any history of implantation failure for the control group and history of at least two or more implantation failures for the case group. The exclusion criteria were as follows: women who were taking medication that had an effect on sexual function, psychological disorders and diseases that had effect on sexual function. Prior to the data collection, written informed consent was obtained from each participant and anonymity of participants was maintained.

\section{Sample size}

The sample size of this study was calculated from the previous study (20) and based on the following formula:

$$
n=\frac{\left(Z_{1-\frac{\alpha}{2}}+Z_{\beta}\right)^{2}\left(S D_{1}^{2}+S D_{2}^{2}\right)}{\left(\mu_{1}-\mu_{2}\right)^{2}},\left(\mu_{1}=4.7, \mu_{2}=6, \alpha=0.05, \beta=0.1, S_{1}=2.4, S_{2}=2.9, Z_{\beta}=1.32, Z_{1-\alpha / 2}=1.96\right)
$$

Considering $90 \%$ power for this study the final sample size in each group calculated to be 90 women.

\section{Measures}

To collect data, we used a demographic questionnaire and the Female Sexual Function Index. The demographic questionnaire included questions about age, age of husband, occupation, educational attainment and the economic status. The Female Sexual Function Index contains 19 questions. Two questions have been provided to measure sexual desire, four for sexual arousal, four for lubrication, three for orgasm, three for satisfaction, and three for measuring pain. The score for each domain was multiplied by a certain factor: 0.6 for desire, 0.3 for arousal and lubrication, and 0.4 for other domains. The minimum and maximum rating for all areas is 2 and 36, respectively (21). Scores below 26.5 are considered reduced sexual function. The Persian version of this questionnaire is available, and its validity and reliability have proven in other studies (22).

All women requested to complete both questionnaires, when one of the researchers (SG) was available, if participants had any questions. 


\section{Statistics}

The data was analyzed using SPSS version 22. The Shapiro-Wilk test was used to test the normal distribution of data. The independent t-test and Chi-Square tests were used for numerical and categorical data respectfully. The Linear regression was used to detect relationship between RIF and sexual function when adjusted for confounding variables. In all cases, we have considered the significance level as $\leq$ 0.05 .

\section{Results}

In this study, 180 infertile women referred to the Ahvaz infertility centers, of which 90 had RIF and 90 had no RIF. The sociodemographic information of both groups is shown in Table 1. With the exception of age (participants in the RIF group were considerably older), women in two groups did not show any significant difference regarding demographic characteristics. Causes of infertility in the RIF group were female factor (33.3\%), male factor (34.4\%), unexplained infertility (32.2\%) and in the group without RIF were female factor (37.8\%), male factor (41.1\%) and unexplained infertility $(21.1 \%),(p=0.239)$ (Table 2$)$. 
Table 1

Socio-demographic characteristics of participants in two groups

\begin{tabular}{|c|c|c|c|}
\hline Variables & $\begin{array}{l}\text { With RIF } \\
n=90\end{array}$ & $\begin{array}{l}\text { Without RIF } \\
n=90\end{array}$ & P-value \\
\hline \multicolumn{4}{|l|}{ Mean \pm SD } \\
\hline $\operatorname{Age}(y)$ & $33.34 \pm 5.34$ & $31.03 \pm 5.56$ & 0.005 \\
\hline Age of marriage(y) & $24.10 \pm 6.26$ & $22.76 \pm 5.29$ & 0.123 \\
\hline Duration of marriage(y) & $9.26 \pm 4.45$ & $8.02 \pm 4.73$ & 0.071 \\
\hline \multicolumn{4}{|l|}{$N(\%)$} \\
\hline Occupation of women & & & 0.816 \\
\hline House maker & $80(88.9)$ & $79(87.8)$ & \\
\hline Employee & $10(11.1)$ & $11(12.2)$ & \\
\hline Education of women & & & 0.879 \\
\hline Primary & $17(18.9)$ & $14(16.7)$ & \\
\hline High school & $16(17.8)$ & $14(15.6)$ & \\
\hline Diploma & $29(32.2)$ & $34(37.8)$ & \\
\hline University education & $28(31.1)$ & $27(30.0)$ & \\
\hline Occupation of men & & & 0.947 \\
\hline Unemployed & $3(3.3)$ & $3(3.3)$ & \\
\hline Self-employee & $42(46.7)$ & $41(45.6)$ & \\
\hline Employee & $32(35.6)$ & $35(38.9)$ & \\
\hline Manual worker & $13(14.4)$ & $11(12.2)$ & \\
\hline Education of men & & & 0.690 \\
\hline Primary & $12(13.3)$ & $8(8.9)$ & \\
\hline High school & $10(11.1)$ & $14(15.6)$ & \\
\hline Diploma & $33(36.7)$ & $33(36.7)$ & \\
\hline University education & $35(38.9)$ & $35(38.9)$ & \\
\hline Economic situation & & & 0.056 \\
\hline Poor & $20(22.2)$ & $9(10.0)$ & \\
\hline Moderate & $60(66.7)$ & $65(72.2)$ & \\
\hline
\end{tabular}




\begin{tabular}{|lll|}
\hline Variables & $\begin{array}{l}\text { With RIF } \\
\mathbf{n = 9 0}\end{array}$ & $\begin{array}{l}\text { Without RIF } \\
\mathbf{n}=\mathbf{9 0}\end{array}$ \\
\hline Good & $10(11.1)$ & $16(17.8)$ \\
\hline
\end{tabular}

Table 2

Fertility and infertility of participants in two groups

\begin{tabular}{|llll|}
\hline Variables & $\begin{array}{l}\text { With RIF } \\
\mathbf{n}=90\end{array}$ & $\begin{array}{l}\text { Without RIF } \\
\mathbf{n = 9 0}\end{array}$ & P-value \\
\hline Mean \pm SD & & & \\
\hline Duration of infertility(Y) & $7.48 \pm 4.49$ & $4.81 \pm 3.29$ & $<0.001$ \\
\hline $\mathrm{N}(\%)$ & & & \\
\hline Cause of infertility & & & 0.239 \\
\hline Men & $31(34.4)$ & $37(41.1)$ & \\
\hline Women & $30(33.3)$ & $34(37.8)$ & \\
\hline Unknown & $29(32.2)$ & $19(21.1)$ & \\
\hline Type of infertility treatment & & & \\
\hline IVF & $71(78.9)$ & $69(76.7)$ & \\
\hline ICSI & $5(5.6)$ & $10(11.1)$ & \\
\hline Frozen fetus & $14(15.6)$ & $11(12.2)$ & \\
\hline
\end{tabular}

As evident in Table 3, the mean scores of different domains of sexual function, including (desire, lubrication, arousal, orgasm, pain, and satisfaction) was significantly lower in the group with RIF in comparison to the group without RIF. Moreover, the total score of sexual function was significantly lower in the group with RIF in comparison to group without RIF $(23.11 \pm 2.24$ vs. $25.99 \pm 2.35, p<0.001)$. Nearly $90 \%$ of infertile women with RIF were sexually dysfunction. 
Table 3

Comparison of female sexual function index in two group with and without RIF

\begin{tabular}{|llll|}
\hline Sexual dysfunction & $\begin{array}{l}\text { With RIF } \\
\mathbf{n = 9 0}\end{array}$ & $\begin{array}{l}\text { Without RIF } \\
\mathbf{n = 9 0}\end{array}$ & p-value \\
\hline Desire & $3.43 \pm .68$ & $4.07 \pm 0.52$ & $<0.001$ * \\
\hline Arousal & $3.77 \pm 0.79$ & $4.34 \pm 0.75$ & $<0.001$ * \\
\hline Lubrication & $3.01 \pm 0.55$ & $3.21 \pm 0.42$ & $0.006^{*}$ \\
\hline Orgasm & $3.56 \pm 0.65$ & $3.91 \pm 0.50$ & $<0.001$ * \\
\hline Satisfaction & $4.60 \pm 0.90$ & $4.99 \pm 0.62$ & 0.001 * \\
\hline Pain & $4.74 \pm 1.09$ & $5.41 \pm 0.64$ & $<0.001$ * \\
\hline Total sexual dysfunction & $23.11 \pm 2.49$ & $25.99 \pm 2.32$ & $<0.001$ * \\
\hline *Significant & & & \\
\hline
\end{tabular}

Table 4 shows the results of linear regression for the relationship between the RIF and the components of sexual function when adjusted for confounding variables. As evident from this table, women with RIF were 0.614 times more likely to have a low sexual desire, were 0.568 and 0.206 times more likely to have low sexual arousal and lubrication. There were 0.334 and 0.321 times more likely to have a weak orgasm and sexual satisfaction. For pain domain, there was not any significant difference between two groups with and without RIF when we entered poor economic status, but when we entered moderate and good economic status, results showed that women with RIF were 0.577 and 0.74 times more likely to have pain during intercourse in comparison with women without RIF $(p<0.05)$. Women with RIF were 2.65 times more likely to have a low overall sexual function score than women without RIF $(p<0.001)$. 
Table 4

Relationship of recurrent implantation failure (RIF) with sexual function using Linear Regression

\begin{tabular}{|lcccccc|}
\hline Variable & Coef & Std error & $\mathbf{t}$ & $\mathbf{p}$ & $95 \% \mathrm{Cl}$ & \\
\hline Sexual desire & -0.614 & 0934 & -6.58 & $<0.001$ & -0.799 & -0.430 \\
\hline Sexual arousal & -0.568 & 0.117 & -4.82 & $<0.001$ & -0.801 & -0.335 \\
\hline Lubrication & -0.206 & -0.075 & -2.72 & 0.007 & -0.355 & -0.056 \\
\hline Orgasm & -0.334 & -0.090 & -3.71 & $<0.001$ & -0.513 & -0.156 \\
\hline Sexual satisfaction & -0.321 & 0.118 & -2.72 & 0.007 & -0.554 & -0.008 \\
\hline Pain & & & & & & \\
\hline Moderate economic situation & -0.577 & 0.144 & -3.99 & $<0.001$ & -0.863 & -0.291 \\
\hline Good economic status & -0.747 & 0.267 & -2.80 & $<0.01$ & -1.300 & -0.194 \\
\hline Total sexual function & -2.658 & 0.378 & -7.17 & $<0.001$ & -3.389 & -1.926 \\
\hline All analyses adjusted for age and the economic status. & & & \\
\hline
\end{tabular}

\section{Discussion}

The purpose of this study was to compare the sexual function between two groups of infertile women with or without a RIF. The findings showed that women with RIF had a low score of all areas of sexual function, including sexual desire, arousal, lubrication, orgasm, satisfaction, and pain. Lo SS, in their study evaluated the sexual function of couples undergoing assisted reproductive techniques. Their results showed that the IVF-treated and IUI-treated groups were similar in terms of scores for sexual dysfunction scores, which is similar to the results of this study (23). Smith et al (24). conducted a study to evaluate the sexual function of women who underwent in-vitro fertilization and found that in the IVF-treated group, $38 \%$ had low libido, $15 \%$ had decreased orgasm, $14 \%$ had vaginal dryness, and $13 \%$ had dyspareunia. Similarly, quality of life of among participants decreased significantly. The results of Smith et al's study are similar to what we found in our study, except for that, we found all domains of sexual function as well as total number of sexual function was lower than that in Smith et al's study. This case is due to the fact that the score of sexual function in Iranian women is lower than that in other countries. A systematic review of 18 studies involving 3419 infertile women showed that $64.3 \%$ of infertile Iranian women suffer from sexual dysfunction (25).

Karli, found that women with poor ovarian reserve and infertility has more sexual dysfunction than women with an unknown cause of infertility (26). In Leiblum's study (27), which examined sexual function in three groups of successful IVF, unsuccessful IVF and adoption a child, showed that women who succeeded in their IVF were more satisfied with their sexual function than that women without success and women who adopted a child. They are similar to our findings. 
According to our investigation, Coşkuner Potur et al (28). performed a study to examine sexual dysfunction in infertile women, found a significant difference between the two groups of fertile and infertile women regarding sexual dysfunction, by this way that in infertile group, the rate of sexual dysfunction was higher. Infertility is well established as a cause of stress and anxiety in women. But it is not clear that whether or not stress cause infertility (29). Also, stress, anxiety and depression have a negative relationship with sexual function in women, with the most negative effect of depression (30).

In the present study, although the total score of sexual function in the group without RIF was not satisfactory, but it was significantly higher than that in the women with RIF.

\section{Limitations Of The Study}

Despite its strengths, this study has certain limitations. Fist we have not recruited women randomly; it means that participants in this study are not representatives of the infertile women of Ahvaz. Second, talking about sexual issues in Iranian culture is a taboo and the information about sexual function may have affected by this issue. Furthermore, we did not assess the stress and anxiety of participants and these two factors may have affected sexual function beside of RIF.

\section{Conclusion}

Women with recurrent implantation failure may be particularly at risk for decreased sexual function. Sexual function problems may have a significant impact on overall quality of life during fertility treatment and should be treated as an important component part of comprehensive care.

\section{Abbreviations}

RIF

Recurrent implantation failure

IVF

In vitro fertilization

IUI

Intrauterine insemination

\section{Declarations}

\section{Acknowledgements}

This study was a MSc thesis by SG. All expenses of this study were provided by Ahvaz Jundishapur University of Medical Sciences, Ahvaz, Iran. We would like to thank all women who participated in this study. 
SG, PA, KH, and ND were contributed to conception of the study. SG collected the data. SG, PA, SG, and $\mathrm{KH}$ were involving in data analyzing and interpretation. SG and PA prepared the manuscript in English. All authors read and approved the final version of the manuscript.

\section{Funding}

This research was supported by Ahvaz Jundishapur University of Medical Sciences under grant (MARC9902).

\section{Availability of data and materials}

Data used in this study will be available upon the request from corresponding author.

\section{Ethics and consent to participate}

The design of the study was approved by the Ethics Board of the Ahvaz Jundishapur University of Medical Sciences (Ref: IR.AJUMS.REC.1399.073). Prior to the data collection, written informed consent was obtained from each participant and anonymity of participants was maintained.

\section{Consent for publication}

Not applicable

\section{Competing interests}

Authors declare that they have no competing interests.

\section{References}

1. Schattman GL, Esteves SC, Agarwal A. Unexplained infertility. Female Reproductive Dysfunction. 2015; $1-13$.

2. Speroff L, Fritz MA. Clinical gynecologic endocrinology and infertility. lippincott Williams \& Wilkins; 2005.

3. Fiedler K, Wurfel W. Effectivity of heparin in assisted reproduction. Eur J Med Res. 2004;9(4):,20714.

4. Raziel A, Friedler S, Schachter M, Kasterstein E. Strassburger D, Ron-El R. Increased frequency of female partner chromosomal abnormalities in patients with high-order implantation failure after in vitro fertilization. Fertil Steril. 2002;78(3):515-9.

5. Yang $X$, Huang $R$, Wang $Y-f$. Liang $X-y$. Pituitary suppression before frozen embryo transfer is beneficial for patients suffering from idiopathic repeated implantation failure. Journal of Huazhong University of Science Technology [Medical Sciences]. 2016;36(1):,127-31.

6. Zargar M, Ghafourian M, Nikbakht R, Hosseini VM, Choghakabodi PM. Evaluating chronic endometritis in women with recurrent implantation failure and recurrent pregnancy loss by 
hysteroscopy and immunohistochemistry. Journal of Minimally Invasive Gynecology. 2020;27(1):116-21.

7. Vander Borght $M$, Wyns C. Fertility and infertility: Definition and epidemiology. Clin Biochem. 2018;62:2-10.

8. Maroufizadeh S, Karimi E, Vesali S, Omani Samani R. Anxiety and depression after failure of assisted reproductive treatment among patients experiencing infertility. International Journal of Gynecology Obstetrics. 2015;30(3):253-6.

9. Boivin J, Griffiths E, Venetis CA. Emotional distress in infertile women and failure of assisted reproductive technologies: meta-analysis of prospective psychosocial studies. BMJ. 2011;342:d223.

10. Facchin F, Somigliana E, Busnelli A, Catavorello A, Barbara G, Vercellini P. Infertility-related distress and female sexual function during assisted reproduction. Hum Reprod. 2019;34(6):1065-73.

11. Safarinejad M. Female sexual dysfunction in a population-based study in Iran: prevalence and associated risk factors. Int J Impot Res. 2006;18(4):,382-95.

12. Direkvand-Moghadam A, Delpisheh A, Direkvand-Moghadam A. Effect of infertility on sexual function: a cross-sectional study. JCDR. 2015;9(5):QC01.

13. Luk BH, Loke AY. Sexual satisfaction, intimacy and relationship of couples undergoing infertility treatment. J Reprod Infant Psychol. 2019;37(2):108-22.

14. Faizal SA, Sidi H, Wahab S, Zin NM, Baharuddin N. Assessment of Marital Dissatisfaction and Its Association with Sexual Dysfunction and Psychiatric Morbidities among Primary Health Attenders in Malaysia. International Medical Journal Malaysia, 2017; 16(2).

15. Karaca N, Karabulut A, Ozkan S, Aktun H, Orengul F, Yilmaz R, et al. Effect of IVF failure on quality of life and emotional status in infertile couples. Eur. J. Obstet. Gynecol. Reprod. Biol, 2016; 206,158 63.

16. Lo SS-t, Kok W-M. Sexual functioning and quality of life of Hong Kong Chinese women with infertility problem. Human Fertility. 2016;19(4):268-74.

17. Monga M, Alexandrescu B, Katz SE, Stein M. Ganiats T. Impact of infertility on quality of life, marital adjustment, and sexual function. Urology. 2004;63(1):126-30.

18. Cocchiaro T, Meneghini C, Dal Lago A, Fabiani C, Amodei M, Miriello D, et al. Assessment of sexual and emotional distress in infertile couple: validation of a new specific psychometric tool. $J$ Endocrinol Investig. 2020;43(12):1729-37.

19. Banerjee S, Mathews M. Quality of life among infertile couples with previously unsuccessful fertility treatment: in-depth exploration with mixed methodology. Iran J Nurs Midwifery Res. 2020;16(3):1109.

20. Zare Z. Amirian M, Golmakani N, Mazlom R, Ahangar ML. Sexual dysfunction in infertile women. IJRM. 2016;14(2):89.

21. Rosen C, Brown J, Heiman S, Leib R. The Female Sexual Function Index (FSFI): A Multidimensional Self-Report Instrument for the Assessment of Female Sexual Function. J Sex Marital Ther. 
2000;26:191-208.

22. Fakhri A, Pakpour AH, Burri A, Morshedi H, Zeidi IM. The Female Sexual Function Index: Translation and Validation of an Iranian Version. J Sex Med. 2020;9:514-23.

23. Lo SS-t, Li RH-W, Kok W-M, Wong GC-y, Ng EH-y. Chan CH-y. Sexual function and quality of life in Chinese couples undergoing assisted reproductive treatment: a prospective cohort study. Human Fertility. 2021;12:1-13. doi:10.1080/14647273.2020.1871518.

24. Smith NK, Madeira J, Millard HR. Sexual function and fertility quality of life in women using in vitro fertilization. J Sex Med. 2015;12(4):,985-93.

25. Omani-Samani R, Amini P, Navid B, Sepidarkish M, Maroufizadeh S, Almasi-Hashiani A. Prevalence of Sexual Dysfunction among Infertile Women in Iran: A Systematic Review and Meta-analysis. Int J Fertil Steril. 2019;12(4):278-83.

26. Karli P, Ozdemir AZ. Sexual dysfunction in in-vitro fertilization (IVF) patients and the effect of ovarian reserve on sexual dysfunction. Annals of Medical Research. 2019;26(8):1610-4.

27. Leiblum SR, Aviv A, Hamer R. Life after infertility treatment: a long-term investigation of marital and sexual function. Hum Reprod. 1998;3(12):3569-74.

28. Coşkuner Potur D, Güngör Satılmış I, Doğan Merih Y, Gün Kakaşç Ç, Demirci N, Ersoy M. Does infertility affect the sexual function and sexual quality of life of women? A case control study. Int $\mathrm{J}$ Sex Health. 2020;32(1):22-32.

29. Rooney KL. The relationship between stress and infertility. Dialogues Clin Neurosci. 2018;20(1):41-7. doi:10.31887/DCNS.2018.20.1/klrooney.

30. Yazdanpanahi Z, Nikkholgh M, Akbarzadeh M, Pourahmad S. Stress, anxiety, depression, and sexual dysfunction among postmenopausal women in Shiraz, Iran, 2015. J Family Community Med. 2018;25(2):82-7. doi:10.4103/jfcm.JFCM_117_17. 